\title{
The Construction of Coordination Mechanism of China's Economic and Social Policy
}

\author{
Fawen Yang, Zhengxia Tang, Jun Li \\ College of Management in Southwest University for Nationalities, Chengdu, 610041, China
}

\begin{abstract}
China's economic and social development of the long-term lack of coordination is caused by various factors, of which, one important factor is the development of social policies tends to lag behind the economic development process. In order to effectively solve the deep-seated contradictions existed in our current economic and social policy coordination process, then we need to build our country's policy coordination mechanism, and thus to promote economic and social development of our country. According to studies, if the combination of policy debate, expert consultation, policy simulation exists, forming a "trinity" of policy coordination mechanisms, it would be able to optimize the structure of China's policy to improve the quality and scientific level of policy, but also reducing the contradictions and conflicts of policies to effectively predict the effect of policy implementation, and finally reach to promote sound and rapid development of China's economy.
\end{abstract}

KEYWORDS: policy coordination; policy debate; Expert Advisory Council; Policy Simulation

\section{INTRODUCTION}

Since the reform and opening up China's rapid economic development, people's living standards are improving, year by year to enhance its international status. However, we are also faced with social issues such as economic policy coordination, which hindered the coordinated development of economy and society, the problem is not only the continuation of a very long time, and there is no pre-experience for reference, therefore, faced with certain risk decisions .With the increasing number of different policies of uncoordinated events, policy coordination and mechanism of constructing research questions, becoming the domestic hot academia concern aroused a lot of attention in the field of multi-disciplinary. Report of the Eighteenth Meeting of the Communist Party of China to put "policy coordination" as promoting China's economic and social development of important content, with particular emphasis on the "perfect coordination mechanism reform, overall planning and coordination of major reform," and specified that the "scientific decision democratic decisionmaking, decision-making of law and improve the decision-making mechanisms and procedures, to play the role of think tanks, while establishing accountability and correction system of democratic decision-making decisions, "and" prior consultation in decision-making and decision-making among the "above reflects our economy the importance of social policy coordination.[1]

Recently, scholars have not yet made the connotation of policy coordination clearly defined, study abroad more representative view there: John P. Burns that "policy coordination" refers to the fusion of two or more policies to evolve and achieve common goals, its purpose is to prevent policy conflicts; [2] in addition, Nina P.Halpern that "policy coordination" on the one hand: different government departments coordinated policy-making process, on the other hand: the evolution of the integration of different policy proposals become a consensus.

Through literature review, we propose a coordinated economic and social policy point of view, that "the economic and social policy coordination" is a dynamic process, it is not only related to economic and social development to adapt, but also throughout the entire process of policymaking, while also epitomized the economic and social policies of both integration status.

In fact, China is still in the special period of social transformation, complex public policy environment makes trouble, hidden behind public policy is the lack of policy coordination in the grim situation. How to pay more attention to economic and social policy coordination at a higher level, 
coordination mechanisms and policy in China, making the country's policy of optimizing structure, improving decision-making ability of the government to improve the quality and scientific level of the policy, although most vigorously to reduce or avoid the country contradictions and conflicts policies implemented effectively predict the effect of policy for China to build a higher level of well-off life and achieve harmony and contribute to optimizing management, this is more important and gives practical significance.

\section{CAUSES OF UNCOORDINATED POLICY: BASED ON THE PERSPECTIVE OF POLICY- MAKING}

For our public policy reasons for the unsatisfactory coordination, Yongqing Liu said: uncoordinated policy benefits due to imperfect coordination mechanism [3]; baoLin Jia believes uncoordinated policy is lack of balance between the central and local performance and results [4]; Xiangming $\mathrm{Hu}$ considers policy uncoordinated policy regime is due to friction between the lack of coordination between the different departments and information feedback [5]. Clearly, more than most scholars are more inclined to be attributed to the lack of coordination of public policies and institutional conflicts of interest. However, in real life, uncoordinated policy more performance for the lack of normative policy, public sex, legal sex, predictability. This shows that we can not just go from the perspective of institutional analysis uncoordinated policy, but should be understood in terms of policy making.

\subsection{Public Policy's Defects on Itself}

Public policy is the implementation and control of state institutions of public authority or other public authority of the organization in a particular historical period, in order to achieve certain political goals, economic goals, cultural objectives and to develop codes of conduct and implementation. Public policy is a series of laws and regulations, executive orders, resolutions of the meeting, relevant regulations and other components. [6] Nature public policy is the government authority to implement the distribution of benefits to the community. Core public policy is public policy to have the authority, and the authority is required to have a normative policy and legal nature to represent the public interest. The so-called "Public policy's defects" refers to an aspect of public policy in any of legality, legitimacy, authority, fairness, impartiality, enforceability, which are lacking or incomplete did exist. [7] In fact, at the time of some of the public policy formulation process, some aspects of the necessary functions, such as defining the problem, the results of forecasting and policy assessments often do not receive due attention and even ignored, but really need science and rational policy-making procedures are not fully established policy up,cause lack of standardized and authoritative. Others, the lack of public policy objective reasonableness, not consistent with the actual situation where some degree of legalization policy weakened, resulting in repeated policy subjective, arbitrary policies and autocratic type. Direct consequence of the policy is flawed public policy did not reflect the public interest, or even contrary to the public interest. In addition, the policy itself is defective in some sectors may become a tool for personal gain.

\subsection{Policy objectives' deviation}

The fact that in the primary stage of socialism and the long-term is China's basic national conditions, the primary goal is to develop the productive forces. Therefore, the focus of the government is to develop economic policies that promote economic growth, inability to take into account the overall development of the whole society, the result is social policy behind the economic policies. Eighteenth Meeting of the Communist Party of China showing that China's economy to be sustained and healthy development, to be on the basis of the development of balance, coordination, sustainability significantly enhanced on to 2020, the Gross Domestic Product per capita income of urban and rural residents Based on the 2010 rise doubled. [8] Therefore, in the next period of time, the focus of work at all levels of government is how to improve social productivity, accelerate economic growth. Multiple levels of government, policy in the transfer process, for consideration of differences and the ability to understand their preferences, each level policy body will be more or less self-interest bias. Facts have proved that the central government looks at the global, local governments can hope to vigorously promote the coordinated development of economy and society, to achieve sound and rapid development. However, under the GDP-oriented performance appraisal pressure, local government or only GDP growth as the top priority, which makes improving people's livelihood and other aspects of social policy in place effective implementation difficult. When economic growth and people's livelihood when there is a conflict, it appeared inevitable economic policy priorities enacted.

\subsection{Single policy-making body, the apparent public participation}

Significant public policy role, it relates to the vital interests of the public, the starting point is to solve public problems, to achieve common goals and to achieve public interest. Public participation as an 
institutionalized democracy, it is an objective requirement for public authorities to obtain information through an open approach, to listen, and have an impact on public policy-making and public governance practices through a variety of interactive feedback behavior. Public participation can be avoided public policy objectives may deviate from the public and even lead to the alienation of public policy. In China, some government departments, followed the traditional way of policy, often without a long-term investigation, nor after careful theoretical analysis, do not listen to the experts detailed demonstration and guidance, but do not discuss through the system, but only by a few leading who wishes to develop and implement policies blind, do not follow the policy-making process. "Mouthpiece", "individual words" phenomenon exists, therefore, became in some places and sectors of public policy making in the habit of setting type. [9] a single decision-making body, the lack of public participation, uncoordinated policies will naturally appear. Simple and casual policy, they can not be expected to bring the policy effects, which makes the actual implementation of policies which greatly reduced. Some policies originally starting point is good, but because of too little coverage or face time to master asymmetry, it will lead to policy can not play its due role.

\section{CONSTRUCTION OF POLICY COORDINATION MECHANISMS: "TRINITY" STRATEGY AND ITS WAY}

Construction of the required policy of economic and social policy coordination mechanism procedures, technology and democratic participation in science are inseparable. To achieve coordinated economic and social policy, we have to turn the policy debate, expert meetings, policy simulation three forms combine to form a "trinity" of policy coordination mechanisms.

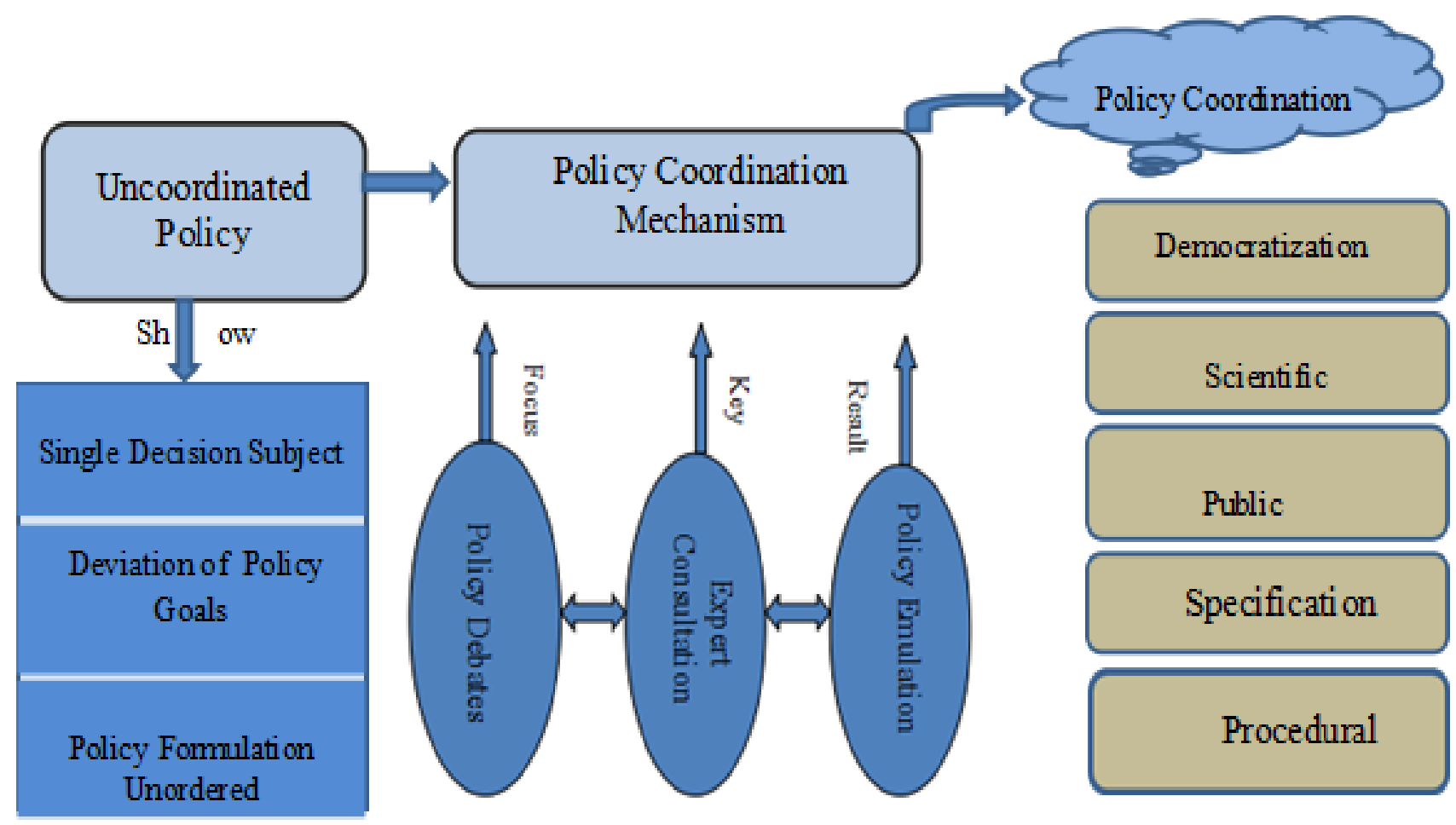

Figure1 Framework of the economy social policy coordination mechanism in China

\subsection{Point of strength of policy coordination mechanisms' construction: the policy carried out through various forms of debate}

In recent years, our country has undertaken a number of policy debate, these policy debate was held, means that China's government will be more stakeholders into the policy-making process in the past. Policy argument, it would be as public participation in public policy-making process has a solid political and legal foundation. Introduced on behalf of groups of citizens and experts, to carry out various forms of policy debate, through the system in the form of public forums, unimpeded expression of interest mechanism, so that the respective interests of the proposition can be fully expressed. Exchange of information more fully, more in-depth understanding of the parties, the policy will not fall into the plight of conflicts and contradictions in policy coordination will be more stable. Because a single decision-making body, policymakers disorder and other reasons, the policy of our country is in trouble, this dilemma only by expanding participation in policy-making body was able to be resolved. This requires the government, experts, media, civic and social organizations to participate 
in the policy debate. Policy debate is only through a comprehensive mechanism for decision-making and information communication mechanism, and to be able to carry out economic and social balanced, overall balance, scientific decision-making, to find the best combination of economic and social development, achieve coordination and balance, and timely share information. In reality, it should require the stakeholders can participate in the policy debate, let public policy on behalf of the public interest as much as possible, so as to coordinate the policies of our nation into a standardized, democratic, scientific procedures, public of the track.

\subsection{The key point to build policy coordination mechanisms: to complete diverse expert consultation}

The expert involved in policy decisions is an advanced form of citizen participation in policy decisions, the introduction of expert evaluation mechanism of public policy in the public sector, between the government and society to solve the problem of asymmetric information, effective means to improve decision-making scientific. Experts in the field of their own research, with the authority. Meanwhile, in public policy, the introduction of an expert system, has a dual role: one which, experts should use their professional knowledge of social issues need to be resolved to conduct a comprehensive investigation, and the formation of the corresponding investigation report, increasing the available policy reliability, thus improving the quality of public policy; on the other, the experts involved in the decision making process of public policy is the policy of the government to implement reasonable suggestions to improve the public and scientific policy-making process, thereby increasing the effectiveness of policy implementation. Therefore, significant public policy needs to support policy advice experts. Public policy think-tank to provide for public policy decisions necessary technology, and other disciplines of knowledge support, making more scientific and rational policy options, such policies can strengthen the public recognition, increase public recognition of the public policy community. In the perfect means of thinktank, the government is necessary to ensure the independence of experts and scholars, and experts and scholars have established smooth communication channels. [10]

\subsection{The foothold of policy coordination mechanisms' Construction: the establishment of multi-purpose policy emulation mode}

All levels of the Chinese government in the formulation of public policy process is often a lack of awareness of the policy simulations, the government only when the will to take remedial action when policies hampered in the actual implementation process, but this time, often policy coordination has been caught in a dilemma dilemma. Therefore, the establishment of policy simulation mechanism is necessary for the effect of policy implementation, we can make use of system dynamics approach to predict the effects of policies and repeatedly simulate policy path in the implementation process, once the policy of conflict and contradiction, timely adjustment and again simulation, and strive to achieve the best. The simulation method is applied to policy research and public policy-making process both international frontier setting process, but also the reality of China's huge demand for social development. Public policy simulation method can provide predictable policy effects of "policy laboratories" for policy makers, and the "road map for policy action." [11] The government should simulate "policy laboratories" in the effects of various policies to decision-makers weigh the choice between the various possible paths; policy implementation in the simulation process development and resource allocation, after the implementation of the policy set analog adjustment program, in order to timely monitoring and corrective policy changes resulting deviation from the real situation. Therefore, the introduction of public policy simulation method, in a way to promote the rational and scientific direction of public policy, providing possible for governments at all levels to enhance the quality of decision making.

\section{CONCLUSION AND OUTLOOK}

In order to effectively address the deep-seated contradictions in economic and social policy coordination processes that exist in our country, we must not only learn from the West and other developed countries in economic and social policy coordination practical experience, but also in the practical application of policy coordination mechanisms continue to improve our economy and society. To this end, we propose the following recommendations for improving the process of China's economic and social development policy coordination system:

\subsection{Adjusting policy direction, optimizing the structure of economic and social policies}

China has made great achievements in economic Meanwhile, the regional development imbalances, weak agricultural base, lagging rural development and farmers' income is slow, urban-rural gap is widening between rich and poor is too poor, social undertakings educational scientific and cultural 
health and environmental protection but not with the economy corresponding development of rapid growth, social development is seriously lagging behind in economic development. In order to coordinate economic and social development, the government needs to develop the economy, and more emphasis on the development of society, specifically, is to develop a series of policies aimed at improving the development of society and social development, the expansion of social development investment. Building a moderately prosperous society and the needs of the economy, environment, resources, and social coordinated development. Therefore, only the common development of coordination of economic and social developmentoriented social policy formulation, so that every citizen can enjoy the economic development outcomes.

\subsection{The implementation of "Trinity" policy coordination mechanism to reduce conflicts and conflict policies}

"Trinity" of policy coordination mechanism is to policy debate, experts will simulate three types of policies combined proved and policymakers to build the required procedures, science and technology, social democratic participation mechanisms for economic policy coordination are inseparable. Policy coordination mechanism not only rely on our governments at all levels, but also to build a platform that should be incorporated into the various elements of the policy up to carry out various forms of policy debate, on the basis of expert meetings on policy simulation simulation. So "Trinity" mechanism, it is bound to reflect public policy on behalf of the public interest. Improve China's policy coordination system, so that policy is more authoritative and legitimacy, to make policy truly represent the public interest, service to the people.

\section{ACKNOWLEDGEMENTS}

The research's financially supported from the key programs of the Postgraduate Innovation by southwest University for Nationalities. (No.CX2014SZ12).

\section{REFERENCES}

[1] Jingtao $\mathrm{Hu}$, Steadfastly advance along the road of socialism with Chinese characteristics in order to build a moderately prosperous society in all respects, People's Publishing House: Beijing, pp.28, 2012.

[2] John P.Burns, Horizon Govement: Policy Coordination in China. Paper prepared for the International conference on Govemance in Asia: Culture, Ethics, Institutional Reform and Policy Change, City University of Hong Kong, HongKong, 2002.

[3] Yongqing Liu, Policy paradox. Theory construction, pp.5, 2009.

[4] Baolin Jia, Executive difficult problem for Policy Coordination Perspective. China Ocean University, pp. 2 2009.

[5] Xiangming Hu, reason "File fight" and countermeasures. Chinese administration, pp.9, 1995.

[6] Taijun Jin, The gets obstruction and digestion of Public Policy Implementation, Guangdong People's Publishing House: Guangzhou, 2004.

[7] Yifan Ouyang, Guobo Zhuang, Public Policy defect analysis. China Youth College for Political Sciences, pp. 22007.

[8] Jingtao $\mathrm{Hu}$, Steadfastly advance along the road of socialism with Chinese characteristics in order to build a moderately prosperous society in all respects, People's Publishing House: Beijing, pp.28, 2012.

[9] Hanzhong Qiu, on the current public policy decisionmaking problems and countermeasures. Tibetan ethnic Institute, pp.7 2003.

[10] Haomiao Chen, Public policymakers. Enterprise Herald, pp.15 2012.

[11] Dayu Li, public policy simulation method: theory, application and prospects. Public Management Journal, pp.10 2011. 